\title{
Influence of Varying Temperature on the Bioactive Compounds of Solanum lycopersicum L. after Post-Harvest Storage
}

\author{
Monika Singh, Ajay Kumar, C. Garima, Shikha Tiwari, Vandana, \\ Satyendra K. Maurya and K.D. Pandey*
}

\author{
Centre of Advanced Study in Botany, Institute of Science, Banaras Hindu University, \\ Varanasi-221005, India \\ *Corresponding author
}

\section{A B S T R A C T}

\begin{tabular}{l} 
K e y w o r d s \\
Antioxidant \\
activity, Lycopene, \\
Post-harvest \\
storage, Solanum \\
lycopersicum L, \\
Total phenol. \\
\hline Article Info \\
\hline $\begin{array}{l}\text { Accepted: } \\
\text { 29 May } 2017 \\
\text { Available Online: } \\
\text { 10 June } 2017\end{array}$ \\
\hline
\end{tabular}

\section{Keywords}

Antioxidant activity, Lycopene, Post-harvest storage, Solanum lycopersicum $\mathrm{L}$, Total phenol.

\section{Accepted:} 10 June 2017
Tomato is one of the most widely consumed vegetable crops and it is an important source of bioactive compounds like lycopene, phenolics, vitamins and ascorbic acid. The content of these bioactive compounds largely depends upon their post-harvest storage. In the present study, the influence of post-harvest temperature on the bioactive compounds was determined. During post-harvest of tomatoes (of two different variety hybrid and local) at two different temperatures $4{ }^{\circ} \mathrm{C}$ in a refrigerator and at room temperature $\left(\max 28^{\circ} \mathrm{C} \min \right.$ $19.2^{\circ} \mathrm{C}$ ) in the laboratory conditions were maintained for 42 days and their activity were analyzed. On storage at room temperature exhibited significant high antioxidant activity in comparison to fruits stored at $4{ }^{\circ} \mathrm{C}$. The total phenol content in freshly harvested hybrid and local tomato fruits were near to $0.05 \mathrm{mg}$ GAE/g fresh wt., which increased in both the variety after storage. The hybrid variety fruits have maximum total phenol content at room temperature while lowest in local fruits stored at $4^{\circ} \mathrm{C}$.The hybrid variety tomato fruits had nearly 74 percent lycopene content more than local variety on the day of harvest. The lycopene concentration gradually increased on the storage for 42 days in both the varieties of tomatoes at both the temperature conditions.

\section{Introduction}

Tomato (Solanum lycopersicum L.) is a second largest and important vegetable crop consumed worldwide. The area under cultivation has continuously increased which shown their economic significance throughout the world (Bodunde et al., 1993). Tomato is one of the significant parts of the human diet and is also an abundant source of large number of bioactive compounds such as carotenoids, phenolics, and ascorbic acid, these compounds having a protective effect against various forms of cancer and cardiovascular diseases (abushita et al., 1997;
Kopsell et al., 2006). Bioactive compounds are non-nutritional constituents that are present in small quantities. Many of these compounds (mainly carotenoids, phenolics and some vitamins) have shown antioxidant activity. It is well established that the consumption of fruits and vegetables has been associated with reduced risk of developing chronic diseases (Holst and Williamson, 2008; Vicente et al., 2009; Yahia 2010). The plant secondary metabolites, antioxidants and phenolics components commonly found in various vegetables provide a fruitful defence 
against oxidative stress from oxidizing agents and free radicals (Matkowski, 2006; Sarikurkcu et al., 2009; Antolovich et al., 2000).

Lycopene is one of the most important constituents of tomato, plays a significant role in many diseases such as cardiovascular disease, diabetes, osteoporosis, liver disease, cataracts, and male infertility. It also reduces oxidative stress and inhibits tumor growth in the liver, lung, prostate, breast, and colon (Obermuller-Jevic et al., 2004; Solis et al., 2013). The unique structural and chemical features of lycopene contribute to specific biological characteristics (Chauhan et al., 2011). The antioxidant activity of lycopene is almost twice than beta carotene. In the human diet tomato can provide a significant proportion of the antioxidants (MartinezValvercle et al., 2002). Lycopene, due to their unique structure protect tissues against oxidative and photo oxidative damage by free radicals or reactive oxygen species (Dembinska-Kiec 2005).

Phenolics, an aromatic ring bearing compounds, are widespread groups of substances in flowering plants. They occur in most of vegetative parts of plants, as well as in flowers and fruits, vegetables, cereals, grains, seeds and drinks. Despite their structural diversity, the groups of compounds are often referred to as "polyphenols". Phenolics are secondary metabolites derived from pentose phosphate, shikimate, and phenylpropanoid. Effect of polyphenols on human cancer cell lines, is most often protective and induced reduction in the number of tumors or their growth (Yang et al., 2001). Ascorbic acid is also known as ascorbate and vitamin $\mathrm{C}$, is a basic compound that belongs to the group of water-soluble vitamins, it has the potential to react with almost all other oxidized free radicals. Therefore, it is used as an antioxidant to prevent diseases such as cancers and cardiovascular diseases (Ahmet et al., 2016).The aim of this work was to determine the lycopene concentration, total phenol content and anti-oxidative properties of tomato fruits under two storage temperatures to know their activity and content of these bioactive compounds.

\section{Materials and Methods}

\section{Collection of tomato fruits and storage}

The tomato fruit of hybrid and local varieties were isolated from the plants of tomato grown under natural conditions at Botanical garden of Banaras Hindu University, Varanasi, India $\left(20^{\circ} 18^{\prime} \mathrm{N}\right.$ and $80^{\circ} 36^{\prime} \mathrm{E}$, elevation $\left.80.71 \mathrm{~m}\right)$ in month of April 2016, in the morning (8 AM).

The selected fruits were mostly reddish green, mature, tight and fresh and almost of same size. Thefruits were stored at room temperature $\left(28^{\circ} \mathrm{C}\right.$ max $\left.-19.2^{\circ} \mathrm{C} \min \right)$ and in a freeze (Model-VAE 183, Videocon) $4^{0} \mathrm{C}$ for 42 days in the laboratory.

\section{Reagents and standards}

All the solvents and reagents used were of analytical grade and purchased from E. Merck (Bangalore, India), Standards Lycopene ( $>5 \%$ purity), Ascorbic acid, Gallic acid were purchased from Sigma Aldrich Chemical co. (USA).

\section{Preparation of standard solutions}

Standard solutions were prepared by dissolving, Gallic and ascorbic acids in methanol and pure lycopene in petroleum ether containing BHT (5ppm). The concentration of all standard solutions 10, 20, 30,40 and $50 \mu \mathrm{g} / \mathrm{ml}$ were prepared, respectively from $0.1 \mathrm{mg} / \mathrm{ml}$ concentration of individual standard solutions. All solutions were stored at $-20^{\circ} \mathrm{C}$. 


\section{Lycopene extraction and estimation}

Lycopene was extracted from tomato fruits according the method described by Chen and Tang (1998). The intensity of color was measured in a UV- Vis Spectrophotometer (U-2600, Hitachi) at $503 \mathrm{~nm}$ using petroleum ether as blank. The maximum absorbance $(\lambda$ peak) of lycopene was determined by absorption spectra between at 300-700 nm (Davis at al. 2003) (Figure 1).

Formula for the estimation of lycopene concentration

Lycopene $(\mathrm{mg} / \mathrm{kg}$ fresh weight $)=\left(\mathrm{A}_{503} \times\right.$ 171.7) / W

Where, $\mathrm{W}$ is the exact weight of tomato added, in grams.

\section{Extraction and analysis of antioxidant activity and total phenolics}

To determine the total phenol content and antioxidant activity, tomato fruits were cut into small pieces. Fresh fruit pieces of $5 \mathrm{gm}$ weight with $50 \mathrm{ml}$ methanol was crushed in mortar pestle and filtered with Whatmann paper No.1. The final volume of filtrate was maintained to $50 \mathrm{ml}$ with methanol.

\section{Antioxidant activity}

Scavenging effect on 1, 1- diphenyl-2-picryl hydrazyl (DPPH)

The DPPH assay is a quick and low cost method, which has been used for the evaluation of the anti-oxidative capacity of natural products (Soler-Rivas et al., 2000). Scavenging effect on DPPH radical was determined by the method reported by with minor modifications. The extracts $(10,20,30$, $40,50 \mathrm{mg}$ in methanol) one $\mathrm{ml}$ was mixed with $4 \mathrm{ml}$ of $0.004 \%$ methanolic solution of
DPPH. The mixture was shaken vigorously and incubated for $30 \mathrm{~min}$ in dark at $25^{\circ} \mathrm{C}$. The absorbance of the resultant was measured at $517 \mathrm{~nm}$ against the corresponding control. The percent of DPPH de-colorization of the samples was calculated according to the formula

$\mathrm{I} \%=\left(\mathrm{A}_{\text {Blank }}-\mathrm{A}_{\text {sample }} / \mathrm{A}_{\text {Blank }}\right) \times 100$

Where, $\mathrm{I} \%$ is percent of inhibition, $\mathrm{A}_{\text {Blank }}$ is the absorbance of the control (without test compound), and $\mathrm{A}$ sample is the absorbance of the test compound. Standard solution of ascorbic acid was prepared by dissolving its $10 \mathrm{mg}$ in $100 \mathrm{ml}$ of methanol $(100 \mu \mathrm{g} / \mathrm{ml}$ stock solution). Lower concentrations of ascorbic acid, 10, 20, 30, 40, 50, $60 \mu \mathrm{g} / \mathrm{ml}$ were prepared by serially diluting stock solution in methanol and absorbance was taken at $517 \mathrm{~nm}$ in a spectrophotometer. (Kumar et al., 2016) (Figure 2).

\section{Estimation of total phenol content}

Total phenol content was estimated using Folin-Ciocalteu reagent as described by Singleton et al., (1999) using Gallic Acid as a standard. Fruit extract $1 \mathrm{ml}$ was mixed with 1 $\mathrm{ml}$ of Folin- Ciocalteu reagent followed by addition of $2 \mathrm{ml}$ of $2 \%$ aqueous sodium carbonate. The mixture was vortexed in a homogenizer and after the addition $6 \mathrm{ml}$ double distilled water, incubated for 20 minutes at room temperature. The absorbance was taken at $650 \mathrm{~nm}$ and $760 \mathrm{~nm}$ in a UV spectrophotometer. The Gallic acid calibration curve was prepared by using different concentration of GA (Figure 1). The total phenolic content was calculated with reference to a gallic acid calibration curve (range $0-60 \mu \mathrm{g} / \mathrm{mL}$ ), and expressed as $\mathrm{mg}$ GA equivalents extract. Formula for estimation of total phenol is based on Gallic acid equivalent (Bray and Thorpe, 1954) (Figure 3). 
$(\mu \mathrm{g})$ Gallic acid $\times$ V

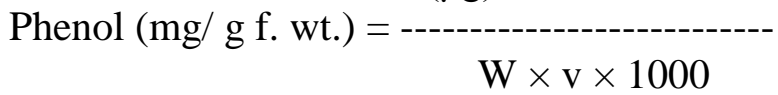

\section{Statistical analysis}

All the data were carried out using the Sigma Plotsoftware (Systat Software, Chicago), and Pearson correlation coefficient was established between absorbance versus concentration.

\section{Results and Discussion}

\section{Effect of storage temperature on bioactive compounds of tomato fruits}

\section{Lycopene content}

Lycopene content of tomato fruits stored at two different temperatures were determined at the interval of 6 days. On the day of harvest, before the storage, lycopene content (23.076 $\mathrm{mg} / \mathrm{Kg}$ ) was high in hybrid variety tomato fruits compared to local variety $(13.507 \mathrm{mg} / \mathrm{Kg})$. Post-harvest storage of tomatoes resulted in gradual increase in the lycopene concentration in both the varieties with the time of storage for 42 days at room temperature and in the freeze $\left(4^{0} \mathrm{C}\right)$. On the 42 day of storage the maximum seven times increase in lycopene content was in hybrid variety stored at room temperature, while the minimum increase of about three times was recorded in local variety at $\left(4^{0} \mathrm{C}\right)$. The results presented in figure 4 revealed that storage of tomato fruits in dark gradually enhanced the lycopene content at room temperature (12.7$39.9^{0} \mathrm{C}$ ) which resulted in high lycopene accumulation compared to storage in freeze $\left(4^{0} \mathrm{C}\right)$ (Figures $4 \mathrm{~A}$ and $\left.\mathrm{B}\right)$.

\section{Total phenol content}

Phenolic compounds are responsible for colour, astringency and flavour (taste and aroma) of fruits and vegetables. The total phenol content was based on the absorbance values of the various extract solutions, reacted with Folin-Ciocalteu reagent and compared with the standard solutions of gallic acid equivalents. The concentration of phenol in hybrid and local varieties of tomato stored at room temperature and $4^{0} \mathrm{C}$, for 42 days was determined and the results have been presented in figure 3. On the first day the total phenol content was near to $0.05 \mathrm{mg} \mathrm{GAE} / \mathrm{gm}$ fresh wt. After the storage of fruits, the phenol content increased in both the variety, but in the hybrid tomato fruits stored at room temperature the total phenol content was highest $(0.354 \mathrm{mg} / \mathrm{g}$ fresh wt. $)$ whereas the lowest was recorded in local fruits stored at $4^{0} \mathrm{C} \quad(0.166 \mathrm{mg} / \mathrm{g}$ fresh wt. $)$. Amount quantification is based on the linear equation obtained from the gallic acid standard curve. The results revealed variety specific phenol content increase and freezing temperature less favored phenol accumulation in tomato fruits (Figures 5 and 6).

\section{Antioxidant activity}

The antioxidant activity increased gradually from day of harvest at both room temperature and at $4^{\circ} \mathrm{C}$.to the $42^{\text {th }}$ days of post-harvesting. Hybrid variety fruits stored at room temperature showed highest increased in antioxidant activity whereas the lowest increase was found in the local variety at $4^{\circ} \mathrm{C}$. The decreasing order of $\%$ free radical scavenging activity (FRSA \%) with reference to ascorbic acid was in the order of -Hybrid room temperature $>$ local room temperature $>$ hybrid $4^{\circ} \mathrm{C}>$ local $4^{\circ} \mathrm{C}$.

The hybrid and local variety stored at $4^{\circ} \mathrm{C}$ showed slight increase, in comparison to antioxidant content of the day of harvest. This results revealed that antioxidant activity of tomato fruits depends on the variety and storage condition and room temperature is 
favorable for increase in the activity measured in the terms of free radical scavenging activity (\%) with reference to ascorbic acid equivalents (Figures 7).

Antioxidants compounds are found in fresh fruits and vegetables, and evidence of their role in degenerative diseases prevention is continuously emerging (Jose et al., 2015). TheLycopene is a red-colored carotenoid and its content differs in tomato varieties and increases with ripening of the fruits. Next to ascorbic acid and $\beta$-carotene, lycopene is one of the main antioxidants in ripe tomatoes (Clinton, 1998; Sies and Stahl, 1998; Ilahy et al., 2011).

Post-harvest storage of tomato fruits at room temperature, increased the lycopene concentration in both varieties of tomato with time. Maximum seven fold $(157.13 \mu \mathrm{g} / \mathrm{ml})$ andlowest four times $(54.56 \mu \mathrm{g} / \mathrm{ml})$ of lycopene concentration in hybrid and local varieties respectively, was noticed. In contrast, increase in the lycopene content of fruit stored at $4^{0} \mathrm{C}$ was meagre in both the tomato verities. Storage of tomatoes between 0 to $12^{\circ} \mathrm{C}$ induces chilling injury and temperature below $12^{\circ} \mathrm{C}$ resulted in lycopene loss in ripe-red tomatoes (King and Ludford, 1983; Farneti et al., 2012).Results in the present study revealed that the hybrid variety is superior to local variety in terms of lycopene content and room temperature storage induced its content, This effect has also been observed earlier (Ajlouni et al., 2001; Toor and Savage, 2007). The increase in redness of tomatoes during ripening is due to lycopene accumulation, in association with the internal membrane system (Grierson \& Kader, 1986). Another point of attraction is that on post-harvest storage at two temperature conditions the amount of total phenol increasing in both varieties at room temperature. However, Local variety had highest amount of total phenol and minimum amount was present in hybrid tomato, stored at $4^{0} \mathrm{C}$. The fresh tomatoes of hybrid variety probably could not tolerate the temperature stress continuously for 42 days which resulted in low phenol content.

Fig.1 Linear curve of Absorbance vs. concentration of standard graph of Lycopene

\section{Lycopene}

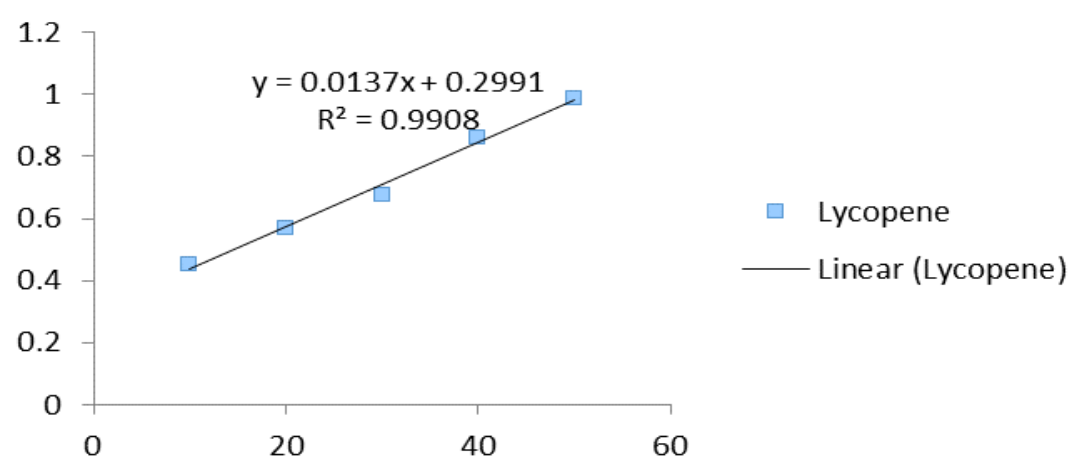


Fig.2 Standard graph of Ascorbic acid

\section{ascorbic}

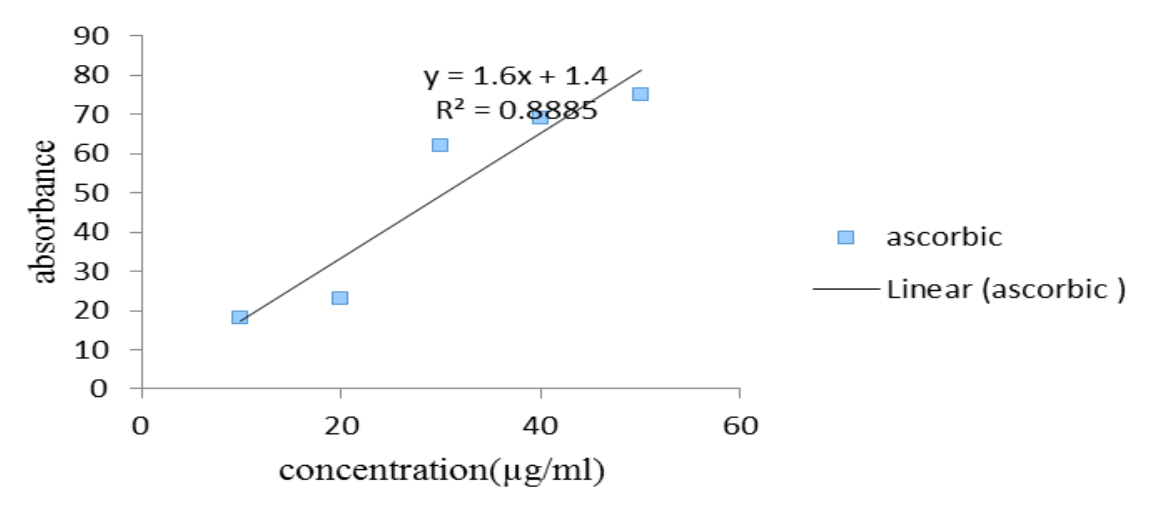

Fig.3 Standard graph of Gallic acid

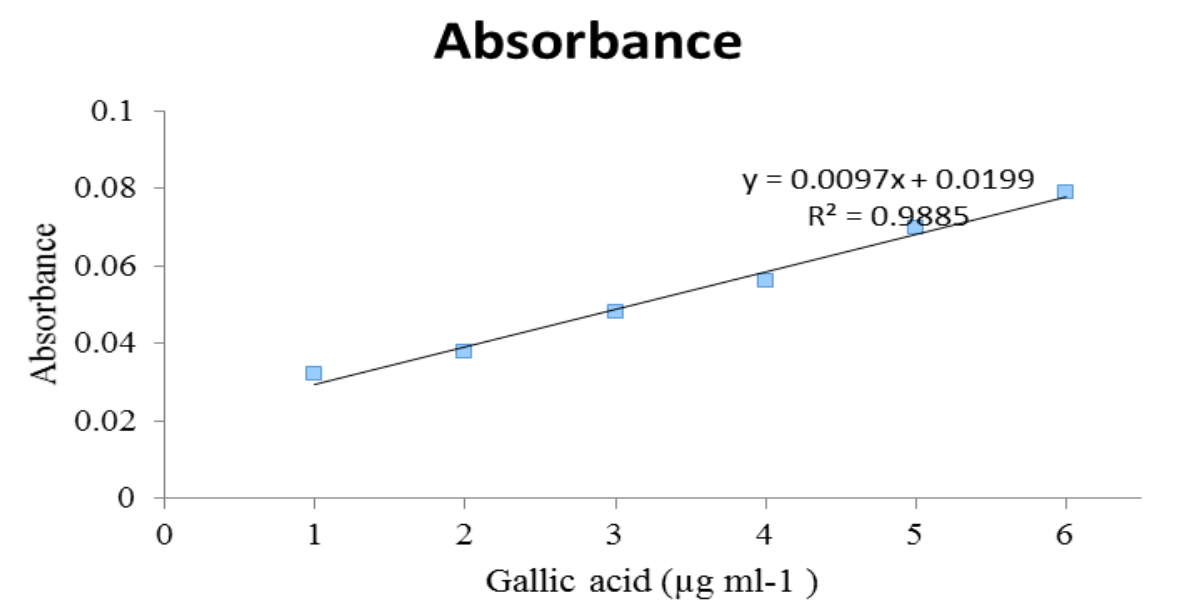

Fig.4 (A) Lycopene concentration in local and hybrid tomato fruits at different temperatures (room temp. min12.7- $\max 39.9^{\circ} \mathrm{C}$ ) and $4^{0} \mathrm{C}$

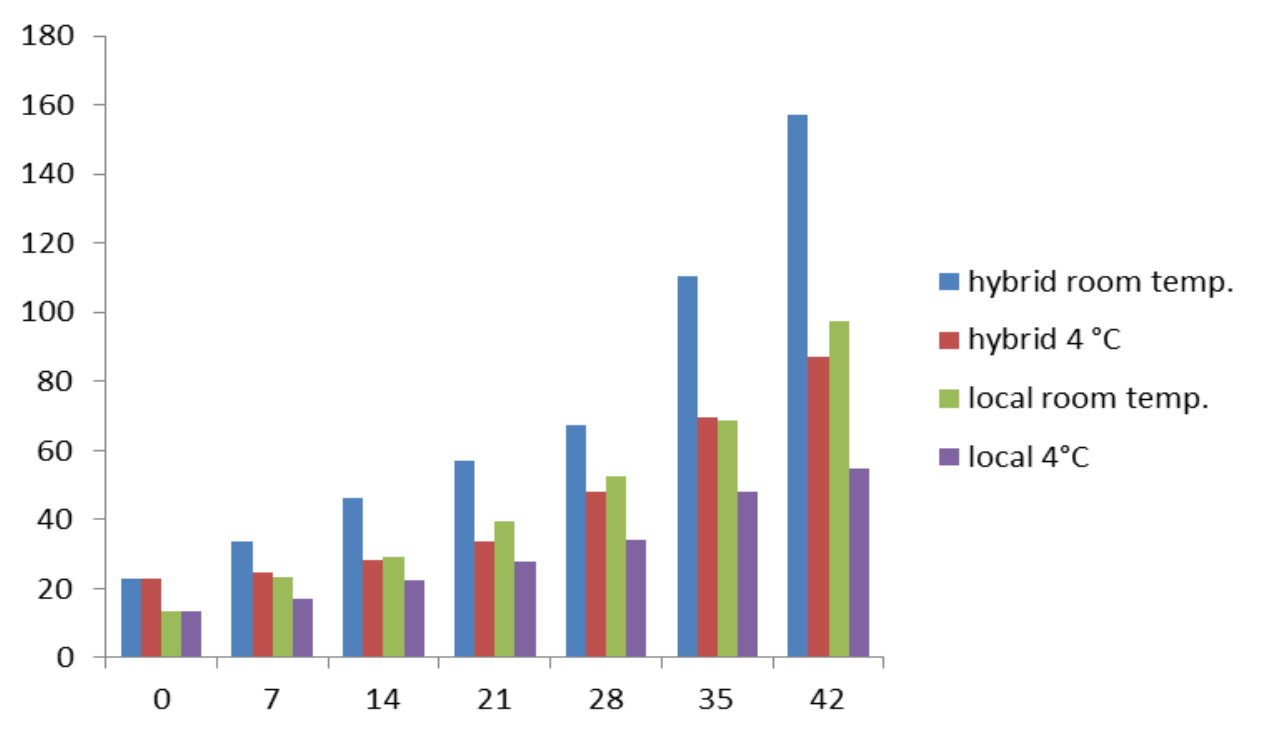


Fig.4 (B) UV-Vis spectrum of lycopene in hybrid and local tomato fruits stored at room temperature. A. (hybrid, 0 day at room temp.) B. (Local, 0 day at room temp.), C. (hybrid, 7 days at room temp.) D. (Local, 7 days at room temp.), E. (hybrid, 42 days at room temp.), F. (Local, 42 days at room temp.)
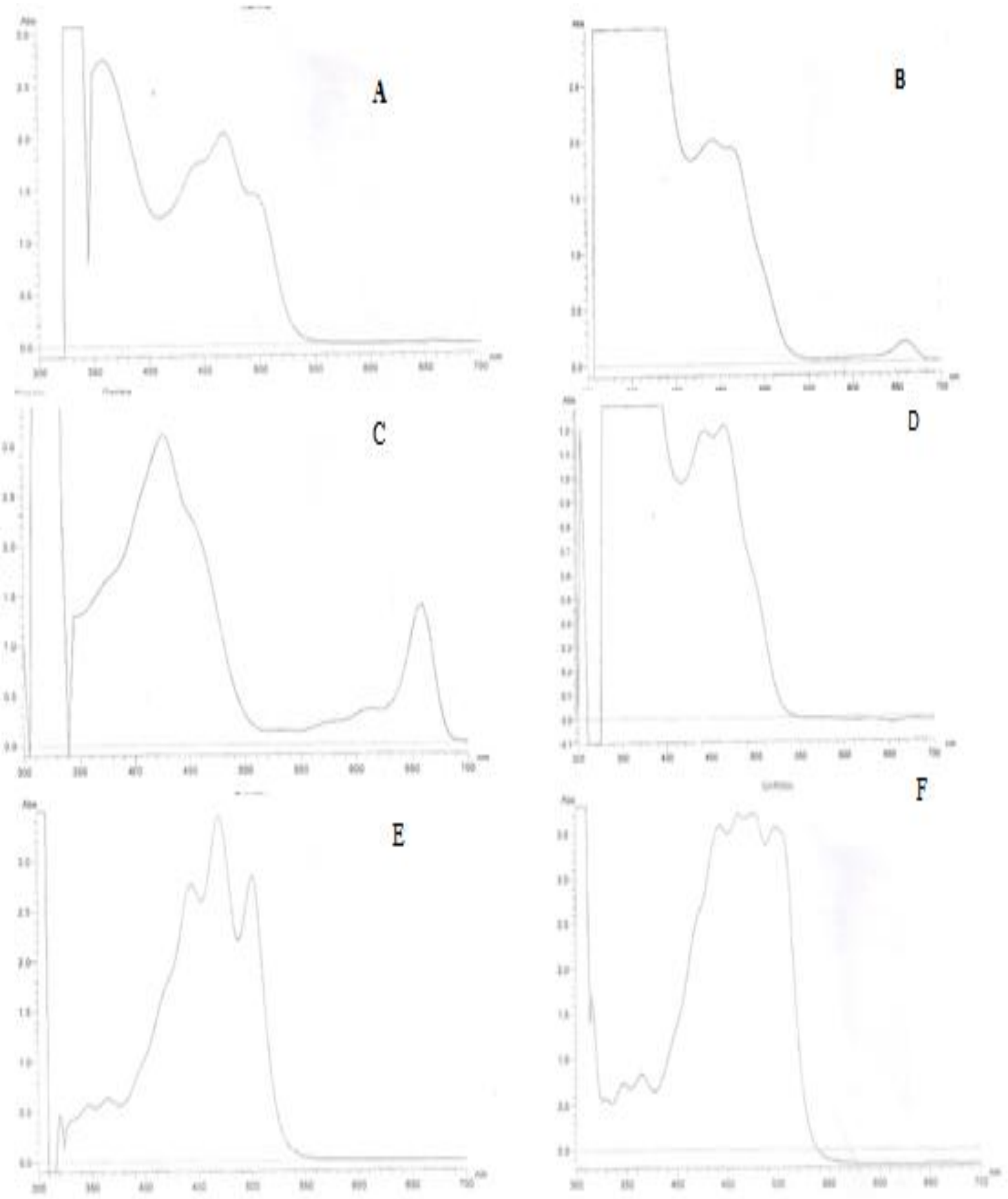
Fig.5 Phenotypic characteristic of hybrid and local tomato fruits under post-harvest storage at room temperature

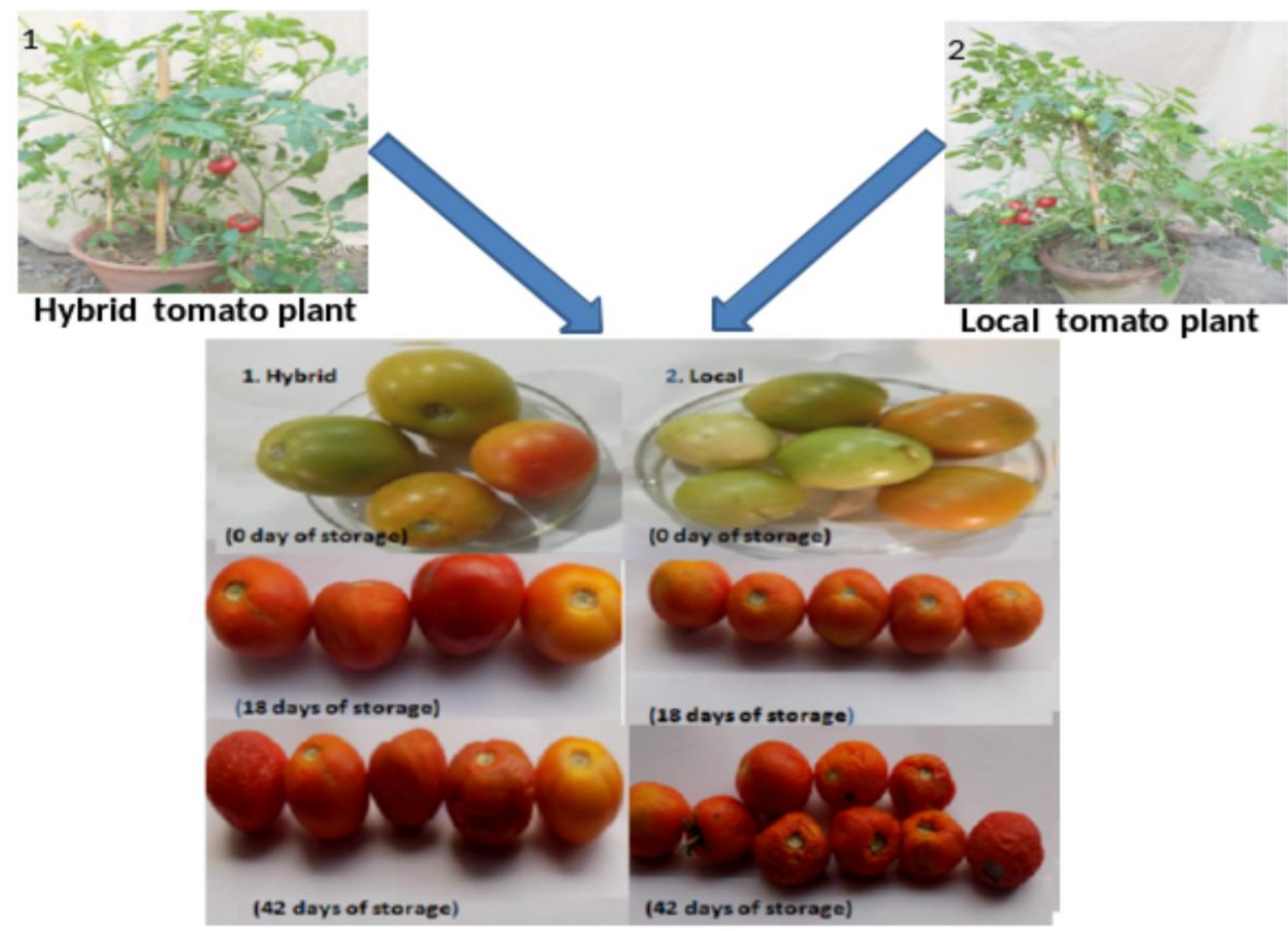

Fig.6 Variations in total phenol content with temperature in hybrid and local varieties tomato fruit stored at room temperature and $4^{0} \mathrm{C}$

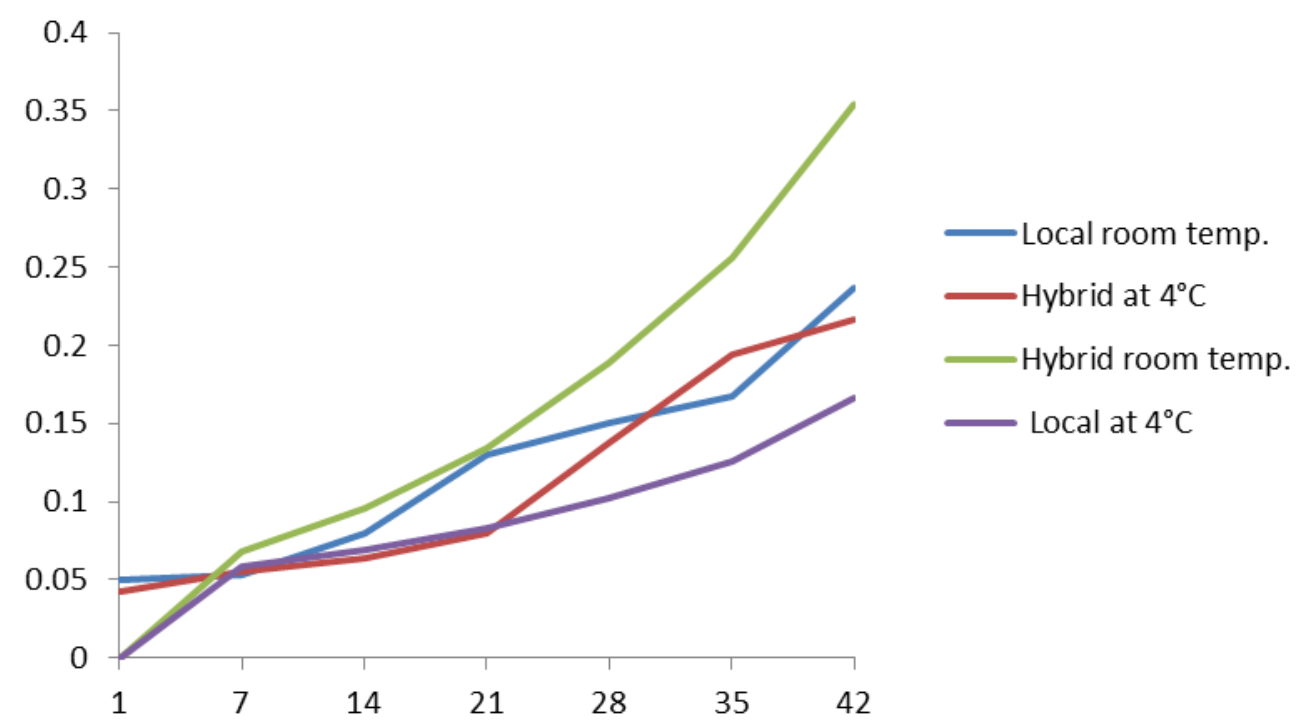


Fig.7 Antioxidant activity of hybrid and local variety fruits of tomato on 42 day, stored at $4{ }^{0} \mathrm{C}$ temperature with reference to ascorbic acid

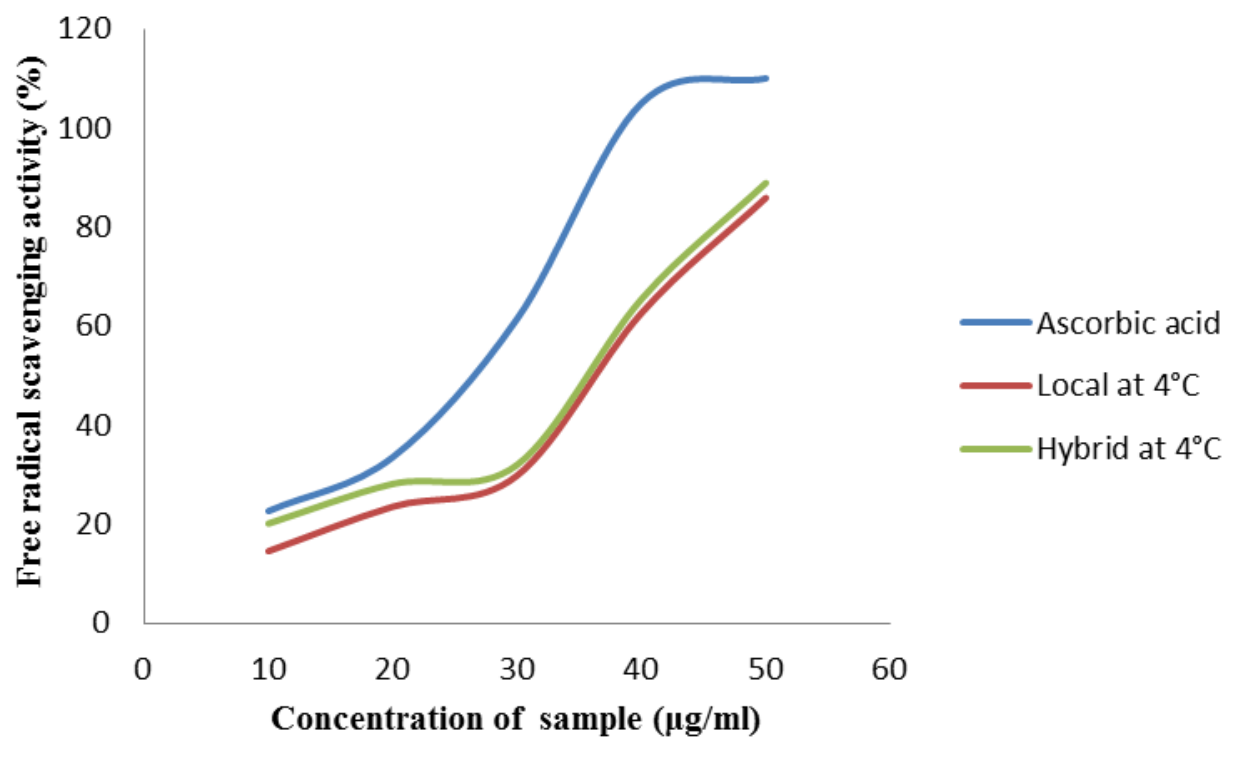

Phenolics were the main antioxidant components, and their total contents were directly proportional to their antioxidant activity (Liu et al., 2009). An antioxidant, when present at low concentrations, significantly delays or prevents the oxidation of cellular components, such as proteins, lipids, carbohydrates, and DNA (Gupta and Sharma, 2014).The important objective of the research work was to estimate the antioxidant activity or percent free radical scavenging activity which also showed an increase in post-harvest storage from initial level of freshly harvested tomatoes. Antioxidant capacity of fruits was significantly correlated only to ascorbic acids. Room temperature storage favored the antioxidant activity in both the varieties however hybrid variety showed higher activity. This result also indicated that the antioxidant activity of local and hybrid variety stored at room temperature was many fold high but less than the ascorbic acid. From the above it is evident that the antioxidant property of tomatoes enhanced several fold on storage particularly at room temperature that is comparatively more but less than ascorbic acid.
The result of this study demonstrate that Postharvest storage of tomatoes showed significant high lycopene content, antioxidant activity, and total phenolic content, which is of pharmacologically importance. The hybrid variety was superior in both the respects than local variety and room temperature storage was more beneficial than refrigerator temperature, for increase in lycopene, total phenol and antioxidant activity.

\section{Acknowledgement}

The work of this research article was supported by the grants from DST-Inspire (Department of Science and Technology, in the form of JRF and SRF to Monika Singh) and University Grant Commission (CAS in Botany), DST-FIST, New Delhi, India. Authors thank to Prof. Madhoolika Agrawal, Head, Department of Botany, Banaras Hindu University, for providing the facilities.

\section{References}

Abushita, A.A., Hebshi, E.A., Dadood, H.G., Biacs, P.A. 1997. Determination of 
antioxidant vitamins in tomatoes. Food Chemistry. 60, 207-212.

Ahmet Unlu, M.D., Onder Kirca, M.D., Mustafa Ozdogan, M.D., Erdinç Nayır, M.D. 2016. High-dose vitamin C and cancer. Journal of Oncological Science. 1, 10-12.

Ajlouni, S., Kremer, S., and Masih, L. 2001. Lycopene content in hydroponic and nonhydroponic tomatoes during postharvest storage. Food Australia. 53, 195-196.

Antolovich, M., Prenzler, P., Robards, K., Ryan, D. 2000. Sample preparation in the analysis of phenolic compounds in fruits. Analyst. 125, 989-1009.

Bodunde, J.G., Erinle, I.D., Eruotor, P.G., Amans, E.B. 1993. Recommendation for the release of four heat tolerant tomato varieties. Technical report approved by the Professional and Academic Board, IFRA, ABU, Zaria, Nigeria. p.165.

Bray, H.G., and Thorpe, W.V.1954. Analysis of Phenolic compounds of Interest in Metabolism. J Meth Biochem Anal. 1, 2752.

Chauhan, K., Sharma, S., Agarwal, N., Chauhan, B. 2011. Lycopene of tomato fame: its role in health and disease. International Journal of Pharmaceutical Sciences Review and Research 10, 99-115.

Chen, B.H., Tang, Y.C. 1998. Processing and stability of carotenoid powder from carrot pule. J Agric Food chem. 46, 2312-2318.

Clinton, S.K. 1998. Lycopene; chemistry,biology and implications for human health and diseases. Nutrition Reviews. 56, 35-51.

Davis, A.R., Fish, W.W., Perkins-Veazie, P. 2003. A rapid Hexane-free method for analyzing lycopene content in watermelon. Journal of Food science. 68, 328-332.

Dembinska-Kiec, A. 2005. Carotenoids: risk or benefit for health. Biochimica et Biophysica Acta. 1740, 93-94.

Farneti, B, Schoutena R.E, Wolteringa, E.J. 2012. Low temperature-induced lycopene degradation in red ripe tomato evaluated by remittance spectroscopy. Postharvest Biology and Technology. 73, 22-27.

Grierson, D., and Kader, A.A. 1986. Fruit ripening and quality. In J. G. Atherton \& J. Rudich (Eds.), the tomato crop: A scientific basis for improvement (pp. 241-280).
London: Chapman and Hall.

Gupta, V.K., and Sharma, S.K. 2014. Plants as natural antioxidants. Natural Product Radiance 5, 326-334.

Holst, B., and Williamson, G. 2008. Nutrients and phytochemicals: From bioavailability to bioefficacy beyond antioxidants. Curr Opin Biotechnol. 19, 73-82.

Ilahy, R., Hdider, C., Lenucci, M.S., Tlili, I., Dalessandro, G. 2011. Phytochemical composition and antioxidant activity of high-lycopene tomato (Solanum lycopersicum L.) cultivars grown in Southern Italy. Sci Hort. 127,255-261.

Jose, A., Villa- Rodriguez, J.A., Carlos, H.P., Yahia, E.M., Ayala-Zavala, J.F., Gonzalez -Aguilar, G.A. 2015.Maintaining Antioxidant Potential of Fresh Fruits and Vegetables After Harvest.Crit Rev Food Sci Nutr. 55, 806-822.

King, M.M., and Ludford, P.M. 1983. Chilling injury and electrolyte leakage in fruit of different tomato cultivars. J Am Soc Hort Sci. 108, 74-77.

Kopsell, D.A., and Kopsell, D.E. 2006. Accumulation and bioavailability of dietary carotenoids in vegetable crops. Trends in Plant Science. 11, 499-507.

Kumar, A., Singh, M., Singh, P.P., Singh, S.K., Raj, P., and Pandey, K.D. 2016. Antioxidant efficacy and curcumin content of turmeric (Curcuma Longa.L) flower. Int J Curr Pharm Re. 8 (3):112-114.

Liu, S.C., Lin, J.T., Wang, C.K., et al., 2009. Antioxidant properties of various solvent extracts from lychee (Litchi chinenesis sonn.) flowers. Food Chem. 114, 577e81.

Martinez-Valvercle, I., Periage, M.J., Provan, G., Chesson, A. 2002. Phenolic compounds, Lycopene and antioxidant activities in commercial varieties of tomato (lycopersicon esculentum). J Sci Food Agr. 82, 323-330.

Matkowski, A. 2006. Plant phenolic metabolites as antioxidants and antimutagens. In: Blume, Y., Smertenko, P., Durzan, D.J. (Eds.),.In: NATO Life Science Monographs, vol. 376. IOS Press, Amsterdam, pp. 129-148.

Obermuller-Jevic, U., Olano-Martin, E., 
Weerden,W.V., Kramer, K., Cross, C.E., Schroder, F.H., Packer, L. 2004. Lycopene and Prostate Health. Oxidants and antioxidants in biology: A conference organized by the Oxygen Club of California (OCC) and co-sponsored by the Linus Pauling Institute. Fess Parker's Double Tree Resort Santa Barbara, California. March 10-13.

Sarikurkcu, C., Arisoy, K., Tepe, B., Cakir, A., Abali, G., Mete, E. 2009. Studies on the antioxidant activity of essential oil and different solvent extracts of Vitex agnus castus L. Fruits from Turkey. Food Chem Toxiol. 47, 2479-2483.

Sies, H., and Stahl, W. 1998. Lycopene:antioxidant and biological effects and its bioavailability in the human. Proceedings of the Society for Experimental Biology and Medicine. 218,121-124.

Singleton, V.L., Orthofer, R., Lamuela-Raventos, R.M. 1999. Analysis of total phenols and other oxidation substrates and antioxidants by means of Folin-Ciocalteu reagent. Method Enzymol. 299, 152-178.

Soler-Rivas, C., Espin, I.C., Wichers, I. 2000. An easy and fast to compare total free radical scavenger capacity of food studys. Phytochemical Analysis. 11, 330-338.
Solis, C.T., Chaverri, J.P., Ramos, M.T., Farfan, D.J., Salgado, A.C., Garcia, N.S., Rico, L.O., Sotelo, J. 2013. Multiple Molecular and Cellular Mechanisms of Action of Lycopene in Cancer Inhibition. Hindawi Publishing Corporation Evidence-Based Complementary and Alternative Medicine, Article ID 705121, 17 pages

Toor, R.K., and Savage, G.P. 2007.Changes in major antioxidant components of tomatoes during post-harvest storage. Food Chemistry. 99, 724-727.

Vicente, A.R., Manganaris, G.A., Sozzi, G.O., Crisosto, C.H. 2009. Nutritional quality of fruits and vegetables. Postharvest Handling: A Systems Approach (Food Science and Technology). 58-106.

Yahia, E.M. 2010. The contribution of fruits and vegetables consumption to human health. In: Fruit and Vegetable Phytochemicals: Chemistry, nutritional and stability, pp. 352. Gonzalez-Aguilar, G. A., AlvarezParrilla, E. and dela Rosa, L., Eds., WileyBlackwell, Iowa

Yang, C.S., Landau, J.M., Huang, M.T., Newmark, H.L. 2001. Inhibition of carcinogenesis by dietary polyphenolic compounds. Ann Rev Nutr. 21, 381-406.

\section{How to cite this article:}

Monika Singh, Ajay Kumar, C. Garima, Shikha Tiwari, Vandana, Satyendra K. Maurya and Pandey, K.D. 2017. Influence of Varying Temperature on the Bioactive Compounds of Solanum lycopersicum. L after Post-Harvest Storage. Int.J.Curr.Microbiol.App.Sci. 6(6): 29973007. doi: https://doi.org/10.20546/ijcmas.2017.606.356 